\title{
QUALIDADE DA ÁGUA DO RESERVATÓRIO DA USINA HIDRELÉTRICA (UHE) DE PETI, MINAS GERAIS ${ }^{1}$
}

\begin{abstract}
Ana Paula de Souza Silva ${ }^{2}$, Herly Carlos Teira Dias ${ }^{3}$, Rafael Kopschitz Xavier Bastos ${ }^{4}$ E Elias Silva
RESUMO - Este trabalho foi desenvolvido no Reservatório da Usina Hidrelétrica (UHE) de Peti, localizado nos Municípios de Barão de Cocais, Santa Bárbara e São Gonçalo do Rio Abaixo, em Minas Gerais, durante o período de setembro de 2004 a maio de 2005, visando avaliar a influência do uso do solo do entorno do reservatório na qualidade da água. Para isso, foram escolhidos cinco pontos no reservatório que representassem os diferentes usos e coberturas do solo e analisados os parâmetros físico-químicos: temperatura, oxigênio dissolvido, condutividade elétrica, $\mathrm{pH}$, turbidez, cor, sólidos totais, sólidos totais fixos, sólidos totais voláteis e sólidos totais em suspensão, em três profundidades de cada ponto de coleta; o parâmetro transparência foi analisado em cada ponto. Os resultados de qualidade da água foram divididos em época de estiagem (setembro, outubro, abril e maio) e chuvosa (novembro, dezembro, janeiro, fevereiro e março) e, no geral, apresentaram variação sazonal. Na época chuvosa, parâmetros como sólidos, turbidez e cor aumentaram a concentração; foi observada também maior variação entre as profundidades na época de estiagem, e à medida que se adentrava no reservatório (montante para jusante) parâmetros como turbidez, cor e sólidos totais em suspensão diminuíam em função da sua própria dinâmica. Pelos parâmetros analisados, não foi possível detectar nitidamente a influência dos diferentes usos do solo na qualidade da água.
\end{abstract}

Palavras-chave: Qualidade da água, uso e cobertura do solo e reservatórios.

\section{WATER QUALITY AND LAND USE AROUND THE RESERVOIR OF THE HYDROELECTRIC POWER STATION OF PETI, MINAS GERAIS}

\begin{abstract}
This work was developed at the Reservoir of the Hydroelectric Power Station (UHE) of Peti, located in the municipalities of Barão de Cocais, Santa Bárbara and São Gonçalo do Rio Abaixo, in Minas Gerais State, Brazil, from September 2004 to May 2005, to evaluate the influence of the land use around the reservoir upon water quality. For this purpose, five points in the reservoir representing the various land plant covers and uses were chosen and the following physical and chemical parameters were analyzed: Temperature, Dissolved Oxygen, Electric Conductivity, pH, Turbidity, Color, Total Solids, Fixed Total Solids, Volatile Total Solids and Total Solids in Suspension in three depths at each point of collection. The parameter Transparency was analyzed in each point. The results of water quality were divided into dry weather period (September, October, April and May), and rainy period (November, December, January, February and March). They usually showed a seasonal variation. In the rainy period, parameters such as solids, turbidity and color increased. A greater variation among the depths in the dry weather period was also observed. When going farther inside the reservoir (from upstream to downstream), parameters such as turbidity, color and total solids in suspension decrease because of their dynamics. By the parameters analyzed, it was not possible to clearly detect the effect of the various land uses on the water quality.
\end{abstract}

Keywords: Water quality, land covers and uses and reservoir.

\section{INTRODUÇÃO}

Entre os recursos naturais essenciais, a água ocupa posição de destaque, pois sua manutenção em condições ideais é extremamente importante para a manutenção da vida no planeta. Porém, em consequência da exploração não sustentável dos recursos hídricos, estes se encontram, em geral, com sérios problemas na qualidade da água, enquanto que a demanda aumenta paulatinamente.

\footnotetext{
${ }^{1}$ Recebido em 11.02.2008 e aceito para publicação em 23.06.2009.

${ }^{2}$ Programa de Pós-graduação em Ciência Florestal da Universidade Federal de Viçosa. E-mail: <apdess@ yahoo.com.br>.

${ }_{3}^{3}$ Departamento de Engenharia Florestal da Universidade Federal de Viçosa. Viçosa, MG. E-mail: <herly@ufv.br>e <eshamir@ufv.br>.

${ }^{4}$ Departamento de Engenharia Cívil da Universidade Federal de Viçosa. Viçosa, MG. E-mail: <rkxb@ufv.br>.
} 
Diversos fatores, como o crescimento populacional, o processo intensivo de urbanização, a expansão da fronteira agrícola e a implantação de indústrias de grande porte, podem ser apontados como responsáveis pelo aumento na demanda de água para a agricultura irrigada, o abastecimento para consumo humano e industrial e a produção de energia elétrica (MULLER, 1996).

O Brasil é um país cujo potencial hídrico estimula a implantação de reservatórios para suprir as necessidades de abastecimento d'água para fins diversos. Porém, a construção de barragens, com a transformação abrupta de um ambiente lótico (rio) em lêntico (lago), provoca alterações nos regimes dos rios e consideráveis desequilíbrios na estrutura físico-química e hidrobiológica do meio aquático, podendo gerar significativos impactos ambientais, muitas vezes negativos, a montante e a jusante do barramento (BASTOS, 1998). O uso e a ocupação do solo nas respectivas bacias de drenagem são também determinantes na saúde dos lagos (CALIJURI,1999).

A mitigação dos impactos e a preservação da qualidade e dos usos múltiplos de um reservatório dependem de manejo integrado, para o que é fundamental o conhecimento aprofundado desses sistemas, incluindo informações sobre a qualidade de suas águas e do uso do solo em seu entorno. O monitoramento da qualidade da água, além de registrar as variações espaçotemporais relaciona os diversos mecanismos do sistema hídrico com toda a sua bacia de drenagem, a exemplo da capacidade de autodepuração (JONG et al., 1995).

Nesse contexto, o reservatório da Usina Hidrelétrica (UHE) de Peti localizado em área de transição entre a Mata Atlântica e o Cerrado, recebe o aporte do rio Santa Bárbara e contém no seu entorno diferentes níveis de usos e, consequentemente, de coberturas do solo, o que se supõe influenciar a qualidade da água.

Com base no exposto, este trabalho teve por objetivo verificar a influência do uso do solo na qualidade da água do reservatório da Usina Hidrelétrica (UHE) de Peti, Município de São Gonçalo do Rio Abaixo, em Minas Gerais.

R. Árvore, Viçosa-MG, v.33, n.6, p.1063-1069, 2009

\section{MATERIAL E MÉTODOS}

\subsection{Caracterização da Área de Estudo}

O Reservatório da Usina Hidrelétrica de Peti, situado entre as coordenadas $19^{\circ} 52^{\prime} 53^{\prime \prime}$ e $19^{\circ} 53^{\prime} 37^{\prime \prime}$ latitude

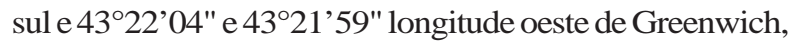
abrangendo parte dos Municípios mineiros de São Gonçalo do Rio Abaixo, Santa Bárbara e Barão de Cocais, estando os dois últimos a montante da barragem, o reservatório é formado pelo represamento da água do rio Santa Bárbara, sub-bacia do Rio Piracicaba e bacia do Rio Doce.

A construção da Usina Hidrelétrica de Peti e a formação do reservatório ocorreram no período de 1941 a 1945, com início da operação em 1946. A barragem possui $86 \mathrm{~m}$ de comprimento e $46 \mathrm{~m}$ de altura com seis comportas para verter água e uma para limpeza. Um túnel de tomada d'água com 40 m de diâmetro e 1.381 $\mathrm{m}$ de extensão leva a água do reservatório para a usina, que desenvolve potência efetiva de $9.400 \mathrm{~kW} / \mathrm{h}$ (FONSECA, 2005).

A extensão do reservatório é de $23 \mathrm{~km}$, com largura máxima de $600 \mathrm{~m}$ e área inundada de $6,776 \mathrm{~km}^{2}$. Aárea da bacia de drenagem é de $708 \mathrm{~km}^{2}$. O volume total do reservatório na cota de $712 \mathrm{~m}$ de altitude é de 42,5 milhões de $\mathrm{m}^{3}$. A cota máxima é de 712,12 $\mathrm{m}$ de altitude e a mínima, de 702,00 m. A profundidade máxima do lago é de 22 m (CEMIG, 2003).

No entorno do reservatório localiza-se a Estação Ambiental de Peti, criada em 1983 em uma área remanescente da Usina Hidrelétrica homônima, num total de 606 ha de áreas preservadas. A Estação Ambiental está se enquadrando como unidade de conservação do tipo Reserva Particular do Patrimônio Natural-RPPN, de acordo com a Lei Federal $n^{\circ}$ 9.985, que instituiu o Sistema Nacional de Unidades de Conservação da Natureza - SNUC. Além da unidade de conservação, a referida bacia hidrográfica possui usos associados ao plantio de eucaliptos, propriedades destinadas à pecuária e agricultura, cidades como Santa Bárbara e Barão de Cocais, que lançam seus rejeitos no rio Santa Bárbara, além de atividades mineradoras na região, principalmente a exploração de minério de ferro (CEMIG, 2003).

Segundo Antunes (1986), de acordo com a classificação de Köppen o clima é do tipo Cwb -tropical de altitude, com verões frescos e estação seca bem 
definida, sendo os meses de outubro a março úmidos e os meses de maio a setembro relativamente secos, com temperatura média anual de $21,7^{\circ} \mathrm{C}$. O solo da região é classificado como Latossolo Vermelho-Amarelo com textura argilosa, afloramentos de rochas, cambissolos e litossolos (CETEC, 1989).

O reservatório da referida usina hidrelétrica localizase em região de extrema importância biológica, no contraforte ocidental da serra do Espinhaço, na zona de transição da Floresta Estacional Subtropical (Mata Atlântica de Interior) com o Cerrado.

Paula et al. (2002) citaram que a bacia do rio Doce, originalmente coberta por florestas, teve sua paisagem inteiramente alterada a partir da segunda metade do século passado. No Alto Rio Doce e nas regiões dos seus afluentes, como o rio Piracicaba e o Santa Bárbara, a implantação do polo siderúrgico no final da metade do século provocou grande impacto nas formações florestais. Nesse sentido, os remanescentes florestais compõem-se de matas secundárias, em diferentes estádios de regeneração, resultantes da exploração seletiva da madeira ou do sistema de corte raso. De acordo com Meira Neto e Martins (2000), trabalhos sobre a estrutura da vegetação são considerados importantes para o conhecimento das comunidades vegetais fragmentadas, pois ocorrem em ampla gama de situações ambientais, com diferentes faces de exposição solar, tipos de solo e condições de umidade, além daquelas geradas pela ação antrópica.

\subsection{Procedimentos Metodológicos}

\subsubsection{Programa de monitoramento da qualidade da água}

Os pontos de monitoramento foram selecionados de forma que representassem os diferentes usos nas margens do reservatório e também o início (a montante do reservatório, localizado na calha do rio Santa Bárbara) e meio do reservatório. Selecionaram-se cinco pontos, conforme a Tabela 1. Foram realizadas nove coletas de amostras de água em frequência mensal, de setembro de 2004 a maio de 2005.

A rotina de coleta, armazenamento e transporte de amostras de água seguiu recomendações técnicas descritas em CETESB (1987).

Para as análises do perfil do reservatório, as coletas foram realizadas com o auxílio de um amostrador de profundidade, a $1 \mathrm{~m}$ da superfície, na profundidade média e no fundo do reservatório, em torno de $3 \mathrm{~m}$ de distância da margem. Essas profundidades variaram em função do nível do reservatório.

As águas do reservatório de Peti foram analisadas com base nos seguintes parâmetros: Temperatura, oxigênio dissolvido, condutividade elétrica, $\mathrm{pH}$, transparência, turbidez, cor aparente, sólidos totais, sólidos totais fixos e sólidos totais voláteis, sólidos totais em suspensão e sólidos sedimentáveis. Tais parâmetros foram selecionados com o intuito de se aferir a influência do aporte externo na qualidade da água. Como exemplo, baixos teores de oxigênio dissolvido e altos valores de condutividade elétrica foram encontrados em locais com baixa qualidade de água. Usualmente, altos valores de sólidos em suspensão indicam altas concentrações de matéria orgânica e inorgânica e, consequentemente nutrientes, mais ainda, esses altos valores redundaram em alta turbidez e baixa transparência da água, o que irá afetar o metabolismo do ecossistema e reduzir a qualidade da água no reservatório (WETZEL 2001).

As variáveis transparência, temperatura, condutividade elétrica, oxigênio dissolvido e pH foram determinadas in situ. A transparência foi medida com disco de Secchi de $30 \mathrm{~cm}$ de diâmetro. O oxigênio dissolvido e a temperatura foram medidos com sonda de profundidade acoplada à um oxímetro DM 04 Digimed. A condutividade elétrica foi determinada com o uso do aparelho DM 03 Digimed e o pH, pelo aparelho Lutron modelo pH 206.

Tabela 1 - Pontos de coleta de amostras de água no reservatório da Usina Hidrelétrica (UHE) de Peti.

Table 1 - Points of collection of water samples in the reservoir of the Hydro-Electric Power Station of Peti.

\begin{tabular}{cl}
\hline Pontos & \multicolumn{1}{c}{ Locais de amostragem } \\
\hline 1 & A montante do reservatório, localizado na calha do rio Santa Bárbara \\
2 & Próximo a margem cujo uso preponderante do solo é mata ciliar \\
3 & Próximo a margem cujo uso preponderante do solo é plantio de eucalipto \\
4 & Próximo a margem cujo uso preponderante do solo é agrícola \\
5 & No meio do reservatório \\
\hline
\end{tabular}


Os demais parâmetros foram determinados no Laboratório de Controle de Qualidade da Água da Divisão de Água e Esgotos da Universidade Federal de Viçosa (UFV), seguindo-se as especificações contidas no Standard Methods for the Examination of Water and Wastewater (APHA, 1998).

Para melhor entendimento da qualidade da água, o banco de dados com os resultados das análises de qualidade da água do Reservatório de Peti foi dividido por época de estiagem e de chuva. Para isso, a CEMIG disponibilizou dados referentes à precipitação pluviométrica e a variação do nível da água no reservatório no período de coleta das amostras.

\section{RESULTADOS E DISCUSSÃO}

\subsection{Precipitação pluviométrica e variação do nível do reservatório}

Na Tabela 2, encontram-se os dados de precipitação pluviométrica mensal durante o período de amostragem, assim como do nível do reservatório nos dias de coleta das amostras de água.

A partir desses dados foram definidas as estações de estiagem e a chuvosa. Os meses de setembro/2004 e outubro/2004, abril/2005 e maio/2005 foram os de menor precipitação, enquanto novembro/2004, dezembro/ 2004, janeiro/2005, fevereiro/2005 e março/2005, os de maior precipitação. No período de estiagem, o nível do reservatório esteve próximo da cota máxima de 712,12 $\mathrm{m}$; de novembro/2004 a março/2005, as comportas foram abertas com a função de conter as cheias e manter o nível do reservatório.

Tabela 2 - Precipitação pluviométrica e variação do nível da água no reservatório da Usina Hidrelétrica (UHE) de Peti no período de coleta de dados.

Table 2 - Precipitation of rainfall and variation of water level in the reservoir of the Hydro-Electric Power Station of Peti in the period of data collection.

\begin{tabular}{lcc}
\hline Meses & Precipitação $(\mathrm{mm})$ & Nível do lago $(\mathrm{m})$ \\
\hline Setembro & 0 & 711,55 \\
Outubro & 56,1 & 709,87 \\
Novembro & 176,7 & 707,5 \\
Dezembro & 343,1 & 707,35 \\
Janeiro & 196,0 & 707,37 \\
Fevereiro & 171,4 & 707,32 \\
Março & 385,4 & 711,92 \\
Abril & 24,3 & 712,01 \\
Maio & 39,9 & 711,58 \\
\hline
\end{tabular}

Fonte: CEMIG (2005).

R. Árvore, Viçosa-MG, v.33, n.6, p.1063-1069, 2009

\subsection{Qualidade da água do reservatório}

A temperatura da água do reservatório variou ao longo do ano de acordo com um padrão uniforme em todos os pontos: queda de temperatura de setembro a novembro/2004 (estiagem, primavera e reservatório mais cheio), aumento da temperatura a partir de dezembro/ 2004 até fevereiro/2005 (chuvas, verão e esvaziamento do reservatório) e novamente queda da temperatura a partir de março (outono e início do enchimento do reservatório). As maiores diferenças entre as profundidades foram verificadas nos meses de setembro/ 2004, outubro/2004, abril/2005 e maio/2005 (época de estiagem e quando o reservatório estava cheio).

Arcova et al. (1998) encontraram valores de temperatura da água de rios no Município de Cunha, Estado de São Paulo, abaixo de $20^{\circ} \mathrm{C}$ em microbacias situadas no Domínio de Mata Atlântica, pois a vegetação que acompanha da zona ripária dessas microbacias proporcionava efetiva proteção contra o aquecimento excessivo da água. No entanto, neste estudo as temperaturas médias estiveram sempre acima de $21^{\circ} \mathrm{C}$, fenômeno típico da capacidade de retenção de calor de massas d'água represadas.

O oxigênio dissolvido (OD) apresentou variações sazonais bem marcadas entre os períodos de estiagem e de chuvas. Na estiagem, as concentrações de OD são mais elevadas, com valores médios na superfície próximos ou acima de $10 \mathrm{mg} / \mathrm{L}$ (supersaturação). No período chuvoso, mesmo na superfície, o OD chegou a cair até 4-6 mg/L.

De acordo com Martins e Sperling (1997), a queda cada vez mais acentuada de oxigênio à medida que se vai da superfície para o fundo do reservatório se deve ao crescente consumo na mineralização de detritos da biomassa algal morta decantante. Outros fatores concorrem para a queda de OD no perfil de profundidade, tal como a penetração de luz solar e a tendência à concentração das algas na superfície. Naturalmente as maiores diferenças entre as profundidades foram observadas na época de estiagem, quando o reservatório estava mais profundo e nos pontos mais no interior.

O mesmo padrão sazonal foi verificado para a condutividade elétrica. No afluente ao reservatório (ponto 1) foi verificada a maior amplitude de variação, entretanto absorvida no reservatório. Nesse parâmetro, a diferença entre as profundidades em comparação 
com a sazonalidade não foi tão nítida. Na estiagem e nas chuvas, a CE no reservatório variou, respectiva e aproximadamente, de 40 - $50 \mu \mathrm{S} . \mathrm{cm}^{-1}$ e 50 - $60 \mu{\mathrm{S} . \mathrm{cm}^{-1}}^{-1}$ Ao estudarem o reservatório de São Simão, PintoCoelho et al. (2004) também verificaram a homogeneidade na estrutura vertical da coluna de água em relação a esse parâmetro.

Raras exceções, os valores de $\mathrm{pH}$ oscilaram acima de 7 em todo o período de coleta e nas três profundidades. Observou-se, neste estudo, uma tendência de elevação do $\mathrm{pH}$ nos períodos de chuvas. A variação entre as profundidades não foi tão nítida perante a sazonalidade, porém naturalmente são um pouco maiores nos períodos em que o reservatório estava mais cheio e nos pontos mais ao seu interior.

A turbidez demonstra, com maior nitidez, os impactos da estação chuvosa. Mais uma vez, as diferenças entre profundidades são mais visíveis com o reservatório mais cheio - época de estiagem e pontos mais a jusante. Verificou-se facilmente que as mais amplas variações e os mais elevados picos de turbidez são bem amortecidos no reservatório por efeito de sedimentação. Por exemplo, o pico médio máximo a montante do reservatório, localizado na calha do rio Santa Bárbara (ponto 1), nas chuvas foi de aproximadamente 200 uT; já no reservatório oscilaram entre 50-80 uT. Entretanto, há que se ressaltar que a turbidez inclui também partículas em suspensão não sedimentáveis, inclusive algas e substâncias em solução, a exemplo do ferro.

Na pesquisa de Arcova e Cicco (1999) foram encontrados valores de turbidez superiores nas microbacias com uso agrícola do que nas florestadas; Arcova et al. (1993) encontraram em bacia hidrográfica recoberta por floresta de Mata Atlântica teores de turbidez entre 0,15 e 4,9 uT, mostrando que a floresta protege o solo contra a erosão e, consequentemente, não carreando partículas para os cursos d'água.

Em relação à cor, destacaram-se também as amplas variações entre os períodos de estiagem e de chuvas. No reservatório, a amplitude de variação chega a ser maior que no afluente: período de estiagem: $20 \mathrm{uC}$ a 35 uC e período de chuvas: $25 \mathrm{uC}$ a $400 \mathrm{uC}$. É preciso lembrar que cor pode ser produzida em um reservatório por deterioração da matéria orgânica, introduzida ou biomassa algal; é preciso também lembrar que, tendo sido medida a cor aparente, os resultados têm influência de turbidez, já que a amostra não foi centrifugada e possuia partículas coloidais e suspensas.

No trabalho de Arcova e Cicco (1999), as microbacias com uso agrícola apresentaram valores maiores de cor aparente do que aquelas com mata. Takino et al. (1984) encontraram valores de $420 \mathrm{uC}$ no rio Casquilho, cuja bacia se encontra preservada pelo Parque Estadual de Campos de Jordão.

Transparência, cor e turbidez são parâmetros intimamente relacionados. Coerentemente, a transparência do reservatório de Peti variou sazonalmente, apresentando redução no período chuvoso, que em muitos pontos chegou a $0,5 \mathrm{~m}$; e no período de estiagem chegou a 1,5 m. Resultado semelhante foi observado no reservatório de São Simão (PINTO COELHO et al., 2004).

Os Sólidos Totais (ST) também apresentaram amplas variações sazonais, porém, ao contrário da maioria dos demais parâmetros analisados, os picos médios mais elevados se davam no período de estiagem. Branco (1999) ressaltou que todos os contaminantes da água, com exceção dos gases dissolvidos, contribuem para a carga de sólidos, os quais podem ser classificados pelas suas características físicas (suspensos e dissolvidos) e químicas (orgânicos e inorgânicos). Cabe também destacar que ST podem ser produzidos em um reservatório, seja por decomposição da matéria orgânica, seja pela proliferação de algas.

Poleto e Carvalho (2004) encontraram valores altos de sólidos totais em torno de $700 \mathrm{mg} / \mathrm{L} \mathrm{na}$ microbacia do córrego do Ipê, em São Paulo, na época chuvosa. No entorno dessa microbacia havia solo exposto e monoculturas, sendo observado carreamento de partículas em época chuvosa para o curso d'água. Entretanto, a princípio, no reservatório de Peti, em que pesem alguns indícios de aporte externo na época de chuvas, as maiores variações parecem ser autóctones, na época em que o reservatório se encontrava mais cheio. De forma coerente, as maiores variações entre profundidades foram observadas nos pontos onde o reservatório estava mais cheio.

Como componente dos ST, os Sólidos Totais Fixos (SF) (fração inorgânica) apresentam incrementos mais concentrados na época de chuvas, o que, nesse

R. Árvore, Viçosa-MG, v.33, n.6, p.1063-1069, 2009 
caso, pode ser indício de aporte externo por escoamento superficial (com destaque para o ponto 3, margeado por floresta de Eucalyptus spp).

Em contrapartida, as variações de sólidos totais voláteis (SV), fração orgânica, parecem melhor espelhar as de ST, reforçando a hipótese da proliferação algal com o reservatório mais cheio, apesar das temperaturas mais baixas (estiagem).

Assim como a turbidez, os dados de Sólidos em Suspensão (SS) demonstram os impactos da estação chuvosa e da sedimentação no reservatório. Por exemplo, o pico médio máximo afluente nas chuvas foi de aproximadamente $150 \mathrm{mg} / \mathrm{L}$; no reservatório, oscilaram entre $60-80 \mathrm{mg} / \mathrm{L}$, logo nos primeiros pontos de coleta e entre $10-15 \mathrm{mg} / \mathrm{L}$ mais no ponto localizado no meio do reservatório. Como os SS incluem as algas, naturalmente nos pontos próximos a barragem registraram-se as variações mais amplas entre as profundidades. Pinto-Coelho et al. (2004) encontraram valores muito maiores de SS na época chuvosa do que na estiagem no Reservatório de São Simão, que é influenciado por atividades agrícolas e pecuárias na bacia de drenagem.

Em síntese, a avaliação da qualidade da água é um processo de análise da natureza física, química e da biota em relação à qualidade natural, aos efeitos humanos e aos usos comprometedores que possam afetar a saúde humana e do sistema aquático. A eficácia dessa tentativa de se medir a qualidade da água muitas vezes não corresponde à expectativa, pois a natureza apresenta capacidade de resposta que nem sempre pode ser numericamente controlada (RAJAR, 1997).

\section{CONCLUSÃO}

Com base nos resultados, apresentam-se as principais conclusões deste trabalho:

Na realidade, o conjunto dos dados indica que o Reservatório de Peti absorva bem os aportes externos provindos do rio que o forma e da área do seu entorno, ou seja, as características apuradas como o bom estado de preservação, com destaque para a área do entorno com grande parte protegida por floresta nativa e para a dinâmica estabilizada, considerando-se a idade do reservatório - mais de 60 anos - permitiram tal constatação.

Além disso, normalmente como ocorre nos reservatórios, a sedimentação e autodepuração fazem com que as águas represadas cheguem mais límpida à barragem, sendo essa informação confirmada pelos teores de turbidez e sólidos em suspensão do início (a montante do reservatório, localizado na calha do rio Santa Bárbara) para o meio do reservatório.

Pelos parâmetros analisados, não foi possível detectar nitidamente a influência dos diferentes usos do solo (floresta nativa, florestas de Eucalyptus spp e uso agrícola) e nem que as variações de qualidade da água se deviam mais claramente a fenômenos sazonais de precipitação pluviométrica.

Constatou-se que a qualidade da água do reservatório era, em geral, boa, com elevados teores de oxigênio dissolvido, $\mathrm{pH}$ em torno da neutralidade, condutividade elétrica em valores relativamente baixos, picos sazonais de turbidez e sólidos absorvidos.

\section{REFERÊNCIAS}

ANTUNES, F.Z. Caracterização climática do estado de Minas Gerais: climatologia agrícola. Informe Agropecuário, v.12, p.9-13, 1986.

APHA, AWWA, WEF. Standard methods for the examination of water and wastewater. 18th ed. Washington, DC: 1998.

ARCOVA, F. C. S.; CICCO, V. Qualidade da água de microbacias com diferentes usos do solo na região de Cunha, estado de São Paulo. Scientia Florestalis, n.56, p.125-134, 1999.

ARCOVA, F. C. S.; CESAR, S. F.; CICCO, V. Qualidade da água em microbacias recobertas por floresta de Mata Atlântica, Cunha, SP. Revista do Instituto Florestal, v.10, n.2, p.185-196, 1998.

BASTOS, R. K. X. Impactos da construção de centrais hidrelétricas relacionados com a água: pressupostos para a avaliação e proposição de medidas mitigadoras. In: SIMPÓSIO BRASILEIRO DE PEQUENAS E MÉDIAS CENTRAIS HIDRELÉTRICAS, 1., 1998, Poços de Caldas. Anais...São Paulo: CMGB, 1998. p.63-75.

BRANCO, S. M. Águas Doces no Brasil: capital ecológico, uso e conservação. São Paulo: Escrituras, 1999.p.1-36. 
CAliJuri, M. C. A comunidade fitoplanctônica em um reservatório tropical (Barra Bonita, SP). 211p., 1999 Tese (Livre-Docência) - Escola de Engenharia de São Carlos, Universidade de São Paulo, São Carlos, 1999.

COMPANHIA ENERGÉTICA DE MINAS GERAIS CEMIG - Gerência de Programas e Ações Ambientais. Plano de negócios: Estação Ambiental de Peti, período 2003-2007. Belo Horizonte: 2003. 39p.

COMPANHIA AMBIENTAL DO ESTADO DE SÃO PAULO - CETESB. Guia de coleta e preservação de amostras de água. São Paulo, 1987, 155p.

FONSECA, L. Informações sobre a UHEPeti. São Gonçalo do Rio Abaixo: 2005.

(Entrevista concedida a Ana Paula de Souza Silva em 18 de abril de 2005)

FUNDAÇÃO CENTRO TECNOLÓGICO DE MINAS GERAIS - CETEC. Composição florística e tipos vegetacionais da Estação de Proteção e Desenvolvimento Ambiental de Peti/CEMIG, MG. Belo Horizonte: SAT/CETEC, 1989. 42p. (Relatório Técnico)

JONG, J.; ROOY, P. T. J. C.; HOSPER, S. H. Living with water: at the crossroads of change. Water Science Technology, v.31, n.8, p.393-400, 1995.

MARTINS, M. L. N.; SPERLING, E. V. Dinâmica do ferro e do manganês no hipolímnio do Reservatório Serra Azul em Minas Gerais. In: CONGRESSO BRASILEIRO DE ENGENHARIA SANITÁRIA E AMBIENTAL, 19., 1997, Foz do Iguaçu. Anais. Foz do Iguaçu, ABES, 1997. CD ROOM.

ENGENHARIA SANITÁRIA E AMBIENTAL, 19., 1997, Foz do Iguaçu. Anais. Foz do Iguaçu, ABES, 1997. CD ROOM.
MEIRA NETO, J. A. A.; MARTINS, F. Estrutura da Mata da Silvicultura, uma floresta Estacional Semidecidual Montana no município de Viçosa MG. Revista Árvore, v.24, n.2, p.151-160, 2000.

MUlleR, A. C. Hidrelétricas, meio ambiente e desenvolvimento. São Paulo: Makron Books, 1996.

PAULA, A. et al. Alterações florísticas ocorridas num período de quatorze anos na vegetação arbórea de uma floresta estacional semidecidual em Viçosa-MG. Revista Árvore, v.26, n.6, p 743$749,2002$.

PINTO-COELHO, R. M. et al. Origens e efeitos do aporte externo de nutrientes em um reservatório tropical de grande porte: Reservatório de São Simão (MG/GO). In: SIMPÓSIO ECOLOGIADE RESERVATÓRIOS: IMPACTOS, AÇÕES DE MANEJO E SISTEMAS EM CASCATA, 2004, Avaré. Simpósio... Botucatu: Instituto de Biociências, UNESP, 2004.

POleto, C.; CARVAlho, S. L. Avaliação da influência da degradação do solo de uma microbacia hidrográfica na qualidade da água do Córrego do Ipê, município de Ilha Solteira-SP. <htpp:// cemac-ufla.com.br/AnaisTrabVoluntários.htm> Acesso: 17 jun. de 2004.

RAJAR, R. "The role of mathematical models, physical models and field measurement in water pollution problems. In: RAJAR, R.; BREBIA, C (Eds.) Water Pollution IV". Boston: Computational Mechanics Publications, 1997. p.545-554.

TAKINO, M.; MAIER, M. H.; STEMPNIEWISKI, H. L. Características físicas e químicas da água em ambientes de altitude elevada - Campos do Jordão. Boletim do Instituto de Pesca. v.11, n. único. p.1-12, 1984.

WETZEL, R. G. Limnology: Lake and River Ecosystems. 3.ed. San Diego: Saunders, 2001. 
